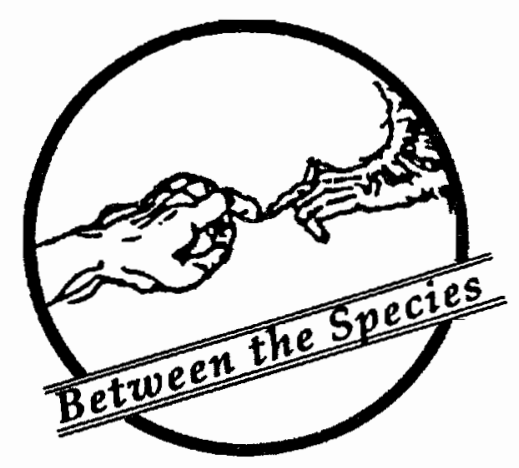

\title{
HARTSHORNE AND THE
} METAPHYSICS OF ANIMAL RIGHTS

\section{Judith Barad \\ Indiana State University}

A review of Daniel Dombrowski's

Hartshorne and the Metaphysics of Animal Rights (Albany: S.U.N.Y. Press, 1987)

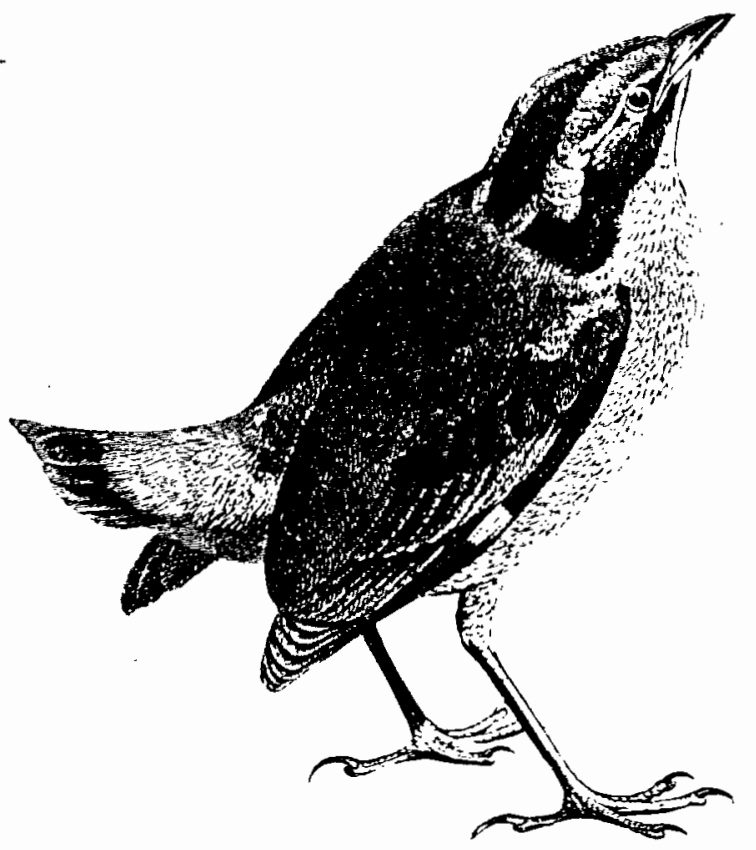

T) rofessor Daniel Dombrowski's book is the first in the ever-growing field of animal rights literature to specifically address the metaphysical basis for the rights of nonhuman animals. Its importance as a seminal work should not be underestimated. Successfully making Hartshorne's metaphysics accessible to the general reader, Dombrowski also uses what Hartshorne says about God and animals to coherently defend philosophic vegetarianism. By grounding animal rights firmly in a metaphysical foundation, Dombrowski gives it a much needed legitimization, obviating the frequently repeated charges that moral rights are arbitrary and fictitious. His clearly written study addresses integral metaphysical questions regarding the position of animals in the overall structure of the universe and the relationship between and the nature of both God and creatures. Dombrowski lucidly and forcefully explains that whether an account of God's nature is one of loving concern or vengeful wrath or uncaring indifference, whether God is conceived as completely separate from the world or
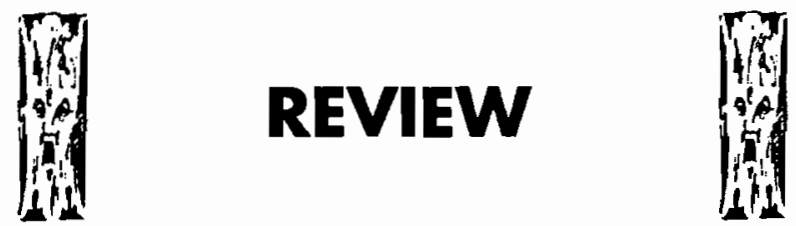
operating, in part, within it are issues that will have a direct bearing on the treatment that is owed to animals. I will review his remarkable feat on a chapter by chapter basis.

Displaying an impressive grasp of the subject matter in his first chapter, Dombrowski contrasts Hartshorne's theories of God and animals with those of the world's great religions. He persuasively argues that God, as depicted in the Old Testament, is either indifferent to or favors the exploitation of animals. However, despite the chapter's many salient qualities, it is the section of the book I had the most quarrel with, since its persuasiveness is in part due to an unbalanced presentation of some of the theologies under consideration. In order to show the preferability of Hartshorne's position on God and animals, Dombrowski overemphasizes Christianity's negative doctrines about animals with little mention of its positive doctrines. Although this is an excellent heuristic device, it leaves the uninformed with an uneven picture. For example, discussing the Old Testament, Dombrowski does not mention man's relationship with animals before his fall, when man was directed by God to be a vegetarian. Yet even in a brief history of how the world's religions view animals, this passage has implications that should not be overlooked. Dombrowski does mention Andrew Linzey's observation that after the fall meat eating is "permitted only as a concession to human sinfulness," but dismisses it after an all too brief consideration.

Turning to "the intellectual framework that supports the dominant Christian view of animals," Dombrowski argues that Aquinas, the best representative of this view, provides "a metaphysical support for the theological belief in human dominion, namely, the control human beings have over their actions, a control that animals lack." Dombrowski offers a series of trenchant arguments against Aquinas' claim. Yet he neglects mentioning that a significant amount of Aquinas' metaphysics would, if taken to its logical conclusion, lead to a more respectful account of the treatment of animals than that which is traditionally ascribed to him. Due to his perception of Aquinas, Dombrowski urges us to adopt the Franciscan pole of Catholic thought rather than the Thomistic pole. I am not convinced by his argument, since St. Francis does not draw an ontological distinction between rocks, trees and oxen whereas Aquinas clearly insists on such a distinction. Happily, though, Dombrowski's refutation of current theologians defending their position on man's dominance over animals is judiciously expounded.

Dombrowski's account of the Eastern religions' views on animals is very absorbing, exhibiting considerable erudition. He points out that unlike Hinduism, which only specifies duties about animals, Jainism and Buddhism acknowledge duties to animals. Generally, the merit of most Eastern religions is that they encourage "us to see human affinity to nature." Dombrowski thinks that by combining the insights of St. Francis with those of Eastern thought we will approach Hartshorne's understanding of the place of animals in creation and have a better understanding of God. The overall virtue of the chapter is that it demonstrates with unusual sensitivity how the relationship between God and creatures issues in different practical effects depending on one's conception of this relationship.

The flow from the first chapter to the second is accomplished by presenting Hartshorne as a great synthesizer between "the best insights of Western theism and Eastern pantheism." He contrasts the classical theistic tenets that God is one but not many, being but not becoming, permanent but not changing with Hartshorne's "panentheism," which holds that both kinds of attributes are included in the divine nature. Dombrowski argues that Hartshorne's conception of God removes the logical difficulties entailed by classical theism's insistence that God loves the world and is involved in it yet is separate from it and unaffected by it. Convincingly, he claims that "Hartshorne's theory of God avoids the vast chasm between Creator and creatures in classical theism while maintaining the traditional Western belief in a personal God who is that than which no greater can be conceived" ( $p$. 39). The most important implication in this chapter for the treatment of animals is that in order to emulate a God who acts as a persuader instead of a tyrant towards His creation, human beings would have to adopt a benevolent rather than a coercive attitude toward animals.

Having established a case for an intimate relationship between God and creatures, in his third chapter Dombrowski argues that once we recognize 
our commonality with animals, we open the way for their "fair treatment" (p. 46). One of the most tired questions any animal rights advocate confronts is, "Well, don't plants feel? How can one non-arbitrarily draw the line of moral concern at animals rather than plants?" Hartshorne's metaphysics can address this question by taking into account the findings of the empirical sciences, findings which are relevant to any argument seeking to base rights upon a being's ontological status. Drawing on theories from contemporary physics, Dombrowski explains that cells are sentient individuals, showing signs of sensitivity to the environment. Plants, like rocks, are multicellular organisms and so are sentient in their parts. But as a whole individual, a plant is not sentient, since it lacks a nervous system. It is the nervous system, composed of the only cells that endure throughout an individual's lifetime, that allows for the interaction between an animal's societies of cells. This interaction issues in a physiologically and psychologically "supercellular individual," an individual per se, not just in each of its parts. In sum, the nervous system accounts for the difference between a plant, where only the cells are sentient individuals (S1) and an animal, where the entire being is a sentient individual as well as its cells (S2). Although the lower form of sentiency found in plants and rocks supports the environmentalist's contention that the whole world is permeated with value, it is the higher grade sentiency of S2 that we have in common with other animals. Thus, unlike plants, animals fall within our moral concern "because they suffer, not simply because their cells suffer" (p. 43). In my view, Hartshorne's distinction between $S 1$ and $S 2$ is as crucial as his account of God for providing a metaphysical basis for the fair treatment of animals.

Our commonality with other animals leads Dombrowski to ask, "If we, as subjects, value our experiences and hence are of value, why not the same to a lesser degree with other subjects with their own implicate order?" For Dombrowski, each individual that experiences its own existence has intrinsic value. Differing from Regan, he concludes the chapter by defending the idea of degrees of inherent value without yielding to the notion that beings of a higher value should exploit those of a lower value, unless in extreme circumstances.
Continuing this theme in the next chapter, one that many animal rights advocates may find the most controversial, Dombrowski argues that human commonality with animals is compatible with a doctrine of hierarchy of value. He claims that "A three-year-old is already beyond the mental level of one of the great apes." The superiority of human beings over animals is due to the fact that we enjoy the conscious understanding of our finitude as well as possessing other abstract abilities. It may be objected that not all members of the human species have these abstract abilities, but Hartshorne, in a statement reminiscent of Darwin, insists that human superiority over nonhuman animals is not absolute but "largely a matter of degree." Agreeing with Hartshorne, Dombrowski notes the importance of a system of abstract symbols, for without it freedom is narrowly curtailed. For instance, only a human being can choose to become a vegetarian or ignore arguments for vegetarianism. Although the human being is the most free of animals, Dombrowski points out that she is also the most dangerous for her freedom permits her to act on the basis of selfinterest rather than ethical concern for others.

The freedom to act on the basis of self-interest leads to Dombrowski's observation that only human beings can make metaphysical mistakes. Interestingly, he notes that animals may, in a way, be closer to metaphysical truth than humans sometimes are, since whereas humans frequently live in "their own world," animals, feeling God through His influence on them, "play their parts well" in relation to Him. Yet humans have the ability to advance beyond this feeling to worship, defined as "consciously" being aware of oneself as an individual who is nonetheless a fragment of the whole of things" (p. 67). In a statement that should help to dispel any suspicion on the reader's part of speciesism, Dombrowski adds "those who live without worship are more like the nonhuman animals than those who live with it." One implication that can be drawn from such passages is that human beings are continuous with other animal species not only in marginal cases but also in ordinary cases when people fail to employ symbolic power. Thus the only quarrel I have with this chapter's conclusion, "that the development of a theory of human commonality with animals is not 
necessarily the thesis that human beings transcend animals in some important ways," is that the word 'some' should be inserted before 'human beings.'

If the fourth chapter may be judged the most controversial, the fifth chapter may be the most appreciated for the excellent quality of its arguments that animals deserve respectful treatment. Dombrowski reasons that the human use of symbols, the same function that sets us apart from the rest of creation, enables us to be ethical beings. Only humans can ask themselves "Whose values ought to give way in the case of conflict?" An often voiced criticism of the animal rights position is that it either prefers animals to humans or detracts from human welfare by recognizing the rights of animals. Offering a powerful, convincing and original argument, Dombrowski responds that ethical concern is not "a pie of a fixed size," so that "giving a slice to animals would deny something to a deserving human being." Ethical concern is unlimited. By refusing to eat animals or kill them for clothing, etc., it is not the case that we are giving animals something reserved for us, but rather "not giving them the bludgeon or the knife of the abattoir."

The same symbolic power that accounts for human transcendence over animals enables us to see ourselves as "trustees for a cosmic end." But if our trusteeship calls upon us to love all forms of life, how can we justify the fact that in order to exist we must treat some other creatures as less important than ourselves? Hartshorne's answer is that value is a matter of degree; it "weakens as one goes 'down' the evolutionary scale from mammals or birds, to fish, to other sea creatures." Hartshorne and Dombrowski share Singer's advocacy of this position, which naturally issues from basing ethics on the metaphysical implications of evolutionary theory.

Hartshorne discusses his degree of values theory in aesthetic terms, claiming that "ethics is subservient to aesthetics." This suggests a tension between his views and those of Dombrowski, for, in my estimation, Hartshorne's aesthetic view seems more compatible with that of an environmentalist than with that of an animal rights advocate. Indeed, Hartshorne's "rough ordering of values" places wildlife management and animals living in the wilderness above concerns for killing animals unnecessarily in laboratories or for the table. I suspect that Dombrowski does not completely agree with Hartshorne on this point, although the disagreement is propitiated.

However, Dombrowski acknowledges that he is using Hartshorne to defend philosophic vegetarianism rather than trying to understand Hartshorne" (p. 3). Attempting to "narrow the gap" between the two positions, he refers to Hartshorne's view "that there is a new level of experience in animals not found in plants" to argue that Hartshorne would agree "that it is only permissible to eat animals if they are treated in a fair way while alive $^{n}$ and are killed without pain. Given modern demands for meat and, consequently, the unlikelihood that factory farms will disappear, Dombrowski insists that if we do not want to be involved in pain and suffering, it is a "practical imperative to become a vegetarian." Thus Dombrowski claims that although Hartshorne does not make any definite statement in favor of vegetarianism, it is the logical outcome of his position.

Drawing on his earlier discussion regarding the individuality of animals and their corresponding value, Dombrowski insists that human concern with species of animals rather than with individuals is both irrational and based on self-interest. He reconciles his concern for animals as individuals with the more environmental concern of Hartshorne by means of several cogent arguments. For instance, he agrees that the "greatest evil we do to animals is to destroy their habitat, because to kill a whole species is to kill massive numbers of individual animals." And he levels Hartshorne's priority for wilderness and wildlife to his more individualistic concerns by noting that our willingness to treat domesticated animals as "increments of capital on modern factory farms" makes it difficult to understand "how we will show any more concern for animals in the wild" unless this concern is based on self-interest. Further, combining concern for individual animals and the environment, Dombrowski maintains that we must give up some of our unnecessary material possessions in order to spare both individual animals, human and nonhuman, and the environment on which all depend.

Chapters six and seven deal with Hartshorne's predecessors, Plato and Wordsworth, who, according to Dombrowski, both have views approxi- 
mating panentheism. The fascinating study of these thinkers explains how panentheism enables us to take animal feelings seriously as elements in God's life and how a consideration of an animal body helps us understand God's nature. In the second chapter, Hartshorne was shown to conceive of God as involved in and affected by the pain and suffering of beings in the world. Since the only beings in the world that experience pain and suffering as whole individuals are animals (both human and nonhuman) the harms inflicted upon them must be understood as being also inflicted upon God. Plato's Timaeus clarifies this interaction between the divine and non-divine natures. In this work, "the World Soul represents a society of which the Demiurge is the one preeminent member," just as the bodily cells of animals form a society "of which the mental part is preeminent." Since "every individual becomes, as it were, a brain cell directly communicating to the World Soul," every individual influences it and is influenced by it. Based on his vivid explication of the World Soul, Dombrowski establishes a historical precedent for his claim that the "ultimate structure of experience is social" and that love is ultimately grounded in God. These chapters show how the deepest insights of poetry and metaphysics merge into one profound truth.

Combining his previously expressed view that the "basic principle human beings must use when trying to understand others is to analogize with what we know ourselves to be" (p. 51) with Hartshorne's emphasis on aesthetics, Dombrowski, in chapter eight, turns to an aesthetic analogy to achieve an understanding of animals. This analogy allows us to penetrate more deeply the "God is love" doctrine, since, in a passage reminiscent of Augustine, Dombrowski argues that variety is an aesthetic good, and not only for human beings, but for God and animals as well." The particular sort of aesthetic feeling Hartshorne has investigated is bird song. The variety of bird song makes it worth studying in itself, for what it can tell us about our own nature, and for what it can tell us about the Divine nature.

Dombrowski has succeeded in showing that Hartshorne's conception of God is compatible with a belief in a God of love. But in what specific ways would a God of love require us to respond to the suffering of animals? Dombrowski concludes the book by arguing that "a necessary, although not sufficient, condition for any fair treatment of animals" is vegetarianism (p. 133), a conclusion warranted by his previous arguments that animals are individuals having their own value, rather than merely instrumental value. But in our contemporary culture, in which meat eating is commonplace, Dombrowski considers our duty to be vegetarian as an act of nonsupererogatory saintliness.

My summary cannot do justice to Dombrowski's exceptionally clear and profound treatment of many very complex themes in Hartshorne's metaphysics, in animal rights, and in the relation between them. He is exceedingly well-versed in the areas of metaphysics, comparative religion, ethics, quantum mechanics, and evolutionary theory, as well as the whole of process philosophy. Some animal rights advocates may be dissatisfied by Dombrowski's defense of the ways in which human beings transcend animality, and some process philosophers may believe that he has pushed Hartshorne too far with his attempt to use process thought to provide a basis for philosophic vegetarianism. However, members of both schools of thought can benefit from a serious perusal of Dombrowski's book. His illuminating study will be a standard for everyone concerned with the relationship between metaphysics and animal rights for many years to come.

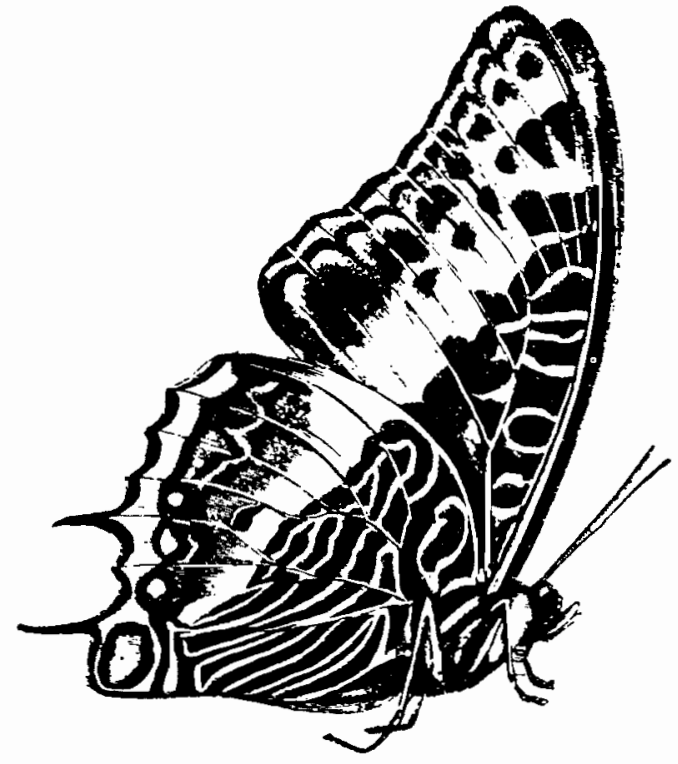

